\title{
Rancang Bangun Sistem Pengukur Massa Tubuh dan Panjang Badan Elektronik Terintegrasi untuk Evaluasi Gizi Balita
}

\author{
WILLY AULIA AKBAR, HENDI HANDIAN RACHMAT \\ Laboratorium Elektronika Teknik Elektro Institut Teknologi Nasional Bandung \\ Email: willyauliaakbar@gmail.com
}

Received 25 September 2017 | Revised 8 November 2017 | Accepted 28 Januari 2018

\begin{abstract}
ABSTRAK
Pada saat ini, monitoring gizi balita dievaluasi berdasarkan perkembangan massa tubuh dan panjang badan balita setiap bulan menggunakan 2 buah alat ukur dan memasukkan data pengukuran secara manual pada grafik Kartu Menuju Sehat (KMS). Proses pengukuran ini relatif lama dilakukan. Untuk mempercepat proses monitoring, maka pada studi ini dilakukan rancang bangun sistem pengukur massa tubuh dan panjang badan elektronik terintegrasi berbasis Personal Computer (PC). Sistem ini memanfaatkan sensor strain gauge dan transducer ultrasonik untuk mengukur massa tubuh dan panjang badan balita. Kedua alat ukur tersebut diintegrasikan dalam sebuah box bayi kayu. Data hasil pengukuran diolah dengan Arduino Nano dan dikirimkan ke PC untuk proses evaluasi, penyimpanan dan penampilan kondisi gizi balita secara otomatis. Dari hasil pengujian, sistem telah berhasil mengukur massa tubuh dan panjang badan dengan nilai kepresisian secara berturut-turut adalah $150 \mathrm{gr}$ dan 0,12 cm. Sistem juga telah dapat mengevaluasi dan menampilkan gizi balita di PC dalam bentuk digital KMS.
\end{abstract}

Kata kunci: gizi balita, massa tubuh, panjang badan, strain gauge, terintegrasi, transducer ultrasonik.

\begin{abstract}
Recently, the toddler's nutrient is evaluated based on a monthly body weight and length progress which are measured by two different devices and analyzed manually from Kartu Menuju Sehat (KMS), toddler's health curve standard. These producers indeed take a time much longer. In order to speed up the monitoring procedures, we designed and implemented a Personal Computer (PC) based integrated body weight scale and body length measurement device system. The system utilized four strain gauge sensors and an ultrasonic transducer module to measure body weight and length, respectively. Both devices were integrated in a toddler wood box. The measurement data was processed using an Arduino Nano and subsequently transmitted to a PC for further automatic evaluating, recording and displaying the toddler's nutrient condition. The experiment results showed that the system has been successful to measure the body weight and length with precision of $150 \mathrm{gr}$ and $0,12 \mathrm{~cm}$, respectively. The system has been able to evaluate and display the toddler nutrient condition on the PC in digital KMS format.
\end{abstract}

Keywords: body length, body weight, integrated system, strain gauge, toddler's nutrient, ultrasonic transducer. 


\section{PENDAHULUAN}

Kesehatan balita merupakan faktor penting yang menjamin kelangsungan hidup generasi berikutnya. Salah satu program yang dilaksanakan pemerintah adalah dengan mengevaluasi tingkat gizi balita. Program ini dilaksanakan melalui unit Puskesmas dan Posyandu guna meningkatkan kesehatan balita di setiap lingkungan perumahan. Masalah gizi adalah hal yang sangat penting dan mendasar dari kehidupan manusia (Depkes, 2013). Kekurangan gizi selain dapat menimbulkan masalah kesehatan (morbiditas, mortalitas dan disabilitas), juga menurunkan kualitas Sumber Daya Manusia (SDM) suatu bangsa (Depkes, 2013). Dalam skala yang lebih luas, kekurangan gizi dapat menjadi ancaman bagi ketahanan dan kelangsungan hidup suatu bangsa. Akan tetapi, sebaliknya kelebihan gizi juga dapat menjadi penyebab risiko utama Penyakit Tidak Menular (PTM) yang juga merupakan salah satu penyebab utama kematian di Indonesia (Depkes, 2013). Hal itulah yang menjadikan bahwa perlu dilakukan pemantauan terhadap gizi balita sebagai parameter penting kondisi kesehatan balita. Menurut Ahli Gizi, dr. Laila Hayati Sp.G (K) mengatakan bahwa obesitas akibat kelebihan gizi pada anak dapat dicegah dengan cara memantau pertambahan massa tubuh dan tinggi badan secara teratur, penghitungan Indeks Massa Tubuh (IMT) tubuh anak secara berkala, aktifitas fisik rutin tiga hingga lima kali seminggu dan melakukan pengontrolan makanan pada anak (Depkes, 2013).

Dalam prakteknya pemantauan kualitas gizi balita melalui pengukuran massa tubuh dan panjang badan pada balita di Posyandu masih memiliki kelemahan (kekurangan) dimana prosedur pengukuran saat ini masih dilakukan secara manual. Pengukuran massa tubuh balita masih dilakukan dengan menggunakan timbangan yang digantungkan dengan kain (timbangan konvesional) sehingga hasilnya relatif kurang akurat. Begitu juga untuk mengukur panjang badan balita masih menggunakan cara dan alat meteran secara manual. Dengan adanya dua alat yang berbeda, maka proses kedua pengukuran ini memerlukan dua tahap pengukuran yaitu menimbang massa tubuh dan kemudian mengukur tinggi badan. Hal ini menyebabkan proses pengukuran memerlukan waktu yang lebih lama. Kemudian untuk sistem pelaporan dan evaluasi perkembangan pertumbuhan balita itu sendiri masih dilakukan secara manual yaitu dengan mencatat setiap hasil pengukuran ke dalam Kartu Menuju Sehat (KMS) balita. Hal ini juga tentu saja membuat proses evaluasi menjadi tidak optimal karena proses evaluasi perkembangan bayi (dilakukan dengan membandingkan antara hasil pengukuran dengan grafik perkembangan balita) dilakukan secara manual. Kondisi ini tentu saja menjadi sebuah tantangan untuk dapat mengembangkan suatu sistem alat ukur massa tubuh dan panjang badan untuk balita yang lebih optimal, akurat, aman, nyaman dan cepat dalam proses pengukurannya. Pengembangan sistem ini diharapkan dapat menjadikan dua alat ukur menjadi satu unit alat ukur dengan dua fungsi (two in one system), sehingga dapat lebih mudah dan efektif dalam pengukuran massa tubuh dan panjang badan balita. Untuk itu dalam penelitian ini dilakukan rancang bangun sistem pengukur massa tubuh dan panjang badan elektronik terintegrasi untuk evaluasi gizi balita menggunakan sensor strain gauge dan transducer ultrasonik.

Pembuatan alat ukur massa tubuh dan panjang badan telah dilakukan oleh beberapa peneliti, diantaranya Fajri (Fajri, 2014) juga mengembangkan alat ukur alat ukur tinggi dan massa tubuh bayi berbasis mikrokontroler atmega8535 dengan sensor fototransistor. Berdasarkan hasil penelitian dan analisis alat yang dirancang dapat mengukur tinggi dan berat badan bayi dengan ketepatan sebesar 98,15\% untuk alat ukur tinggi badan dan 95,59\% untuk alat ukur berat badan. Spesifikasi alat yaitu massa beban (bayi) minimum yang dapat diukur dengan alat ini adalah $2 \mathrm{~kg}$ dan panjang atau tinggi minimum yang dapat diukur adalah $60 \mathrm{~cm}$. Kurang dari tinggi tersebut tidak dapat terdeteksi lagi oleh alat tersebut. Adanya persen kesalahan 
diakibatkan karena kurang tepatnya cahaya yang diterima oleh sensor fototransistor dari sumber cahaya pada alat panjang badan dan kurang sempurnanya pegas yang digunakan hingga tidak terlalu sensitif dalam mengukur berat badan. Selanjutnya juga ada penelitian pengembangan juga mengembangkan sistem pengukur tinggi dan massa tubuh untuk posyandu menggunakan mikrokontroler atmega8535 (Kusumah, dkk, 2015). Pengukur tinggi dan berat badan menggunakan alat ultrasonik PING dimana sistem ini bekerja untuk mengambil data tinggi balita yang akan dikirimkan ke mikrokontroler untuk ditampilkan ke LCD 16x2 dengan satuan $\mathrm{cm}$ dan strain gauge sebagai alat ukur berat badan. Pada penelitian lainnya (Anindya, S.F. dan Rachmat, H.H., 2015) telah juga digunakan transducer ultrasonik tipe HC-SR04 yang telah berhasil mengukur jarak objek sampai dengan $175 \mathrm{~cm}$. Hal ini menunjukkan bahwa transducerultrasonik dapat digunakan untuk mengukur panjang balita yang lebih pendek dari $175 \mathrm{~cm}$.

Dari penelitian yang telah dilakukan terdapat kelebihan dan kekurangan yang dapat menjadi sebagai bahan referensi untuk dapat mengembang alat ukur massa tubuh dan panjang dengan lebih baik. Kemudian dari penelitian yang sudah dilakukan hanya menampilkan hasil pengukuran saja. Padahal akan lebih baik bila hasil pengukuran dapat disimpan. Oleh karena itu dalam penelitian ini dikembangkan alat ukur massa tubuh dan panjang badan yang terintegrasi dengan $L a p t o p P C$, dimana hasil pengukuran akan ditampilkan dan juga disimpan pada basis data. Selain itu, sistem ini dirancang untuk dapat mengevaluasi kondisi gizi balita secara lebih cepat dengan cara menampilkan hasil pengukuran pada Kartu Menuju Sehat Digital secara otomatis. Dengan adanya alat pengukur massa tubuh dan panjang badan balita ini maka diharapkan proses evaluasi, pencatatan dan pemantauan perkembangan gizi balita akan diolah secara digital dan otomatis dengan komputer, sehingga dapat mempercepat proses evaluasi gizi. Hal ini bertujuan agar dapat meningkatkan pelayanan kesehatan pada masyarakat dimana data hasil pengukuran dapat dievaluasi lebih cepat, serta data dapat disimpan dan dilaporkan secara berkala.

\section{METODOLOGI}

Pada bab ini akan dibahas metode pelaksanaan rancang bangun sistem alat ukur elektronik massa tubuh dan panjang badan yang dibagi dalam beberapa tahap yaitu dari tahap awal sampai tahap penyelesaian. Secara umum sistem ini dibangun dari beberapa perangkat seperti yang terlihat pada blok diagram sistem (Gambar 1). Sistem terdiri dari perangkat keras elektronik, perangkat keras mekanik dan perangkat lunak. Dimana perangkat keras elektronik terdiri dari alat ukur massa tubuh, alat ukur panjang badan, modul pengkondisi sinyal, modul pemrosesan sinyal, display LCD, komunikasi serial dan sebuah perangkat Laptop PC. Untuk perangkat keras mekanik yaitu terdiri dari bahan-bahan untuk membuat box alat ukur panjang badan dan massa tubuh untuk balita. Untuk perangkat lunak terdiri dari perangkat lunak 1 pada modul pemroses sinyal dan perangkat lunak 2 pada Laptop $P C$.

Pada implementasi alat ukur massa tubuh dan panjang badan perangkat keras yang digunakan yaitu sensor strain gauge sebagai sensor massa tubuh, untuk sensor panjang badan menggunakan transducer ultrasonik HC-SR04, modul HX771 sebagai modul pengkondisi sinyal, modul pemroses sinyal digunakan modul Arduino Nano, kemudian modul display LCD 20x4 dan catu daya $5 \mathrm{~V}$. Untuk perangkat keras mekanik bahan-bahan yang dipilih dan digunakan berupa kayu bahan jati yang aman untuk balita. Untuk perangkat lunak menggunakan aplikasi Arduino IDE dan juga aplikasi PLX-DAQ. Alat ukur massa tubuh dan panjang badan yang diimplementasikan memiliki spesifikasi dengan ketelitian 100 gram dengan jangkauan 0 sampai dengan $30 \mathrm{~kg}$ untuk massa tubuh dan ketelitian $1 \mathrm{~cm}$ dengan jangkauan 11 sampai dengan $103 \mathrm{~cm}$ untuk panjang badan. 


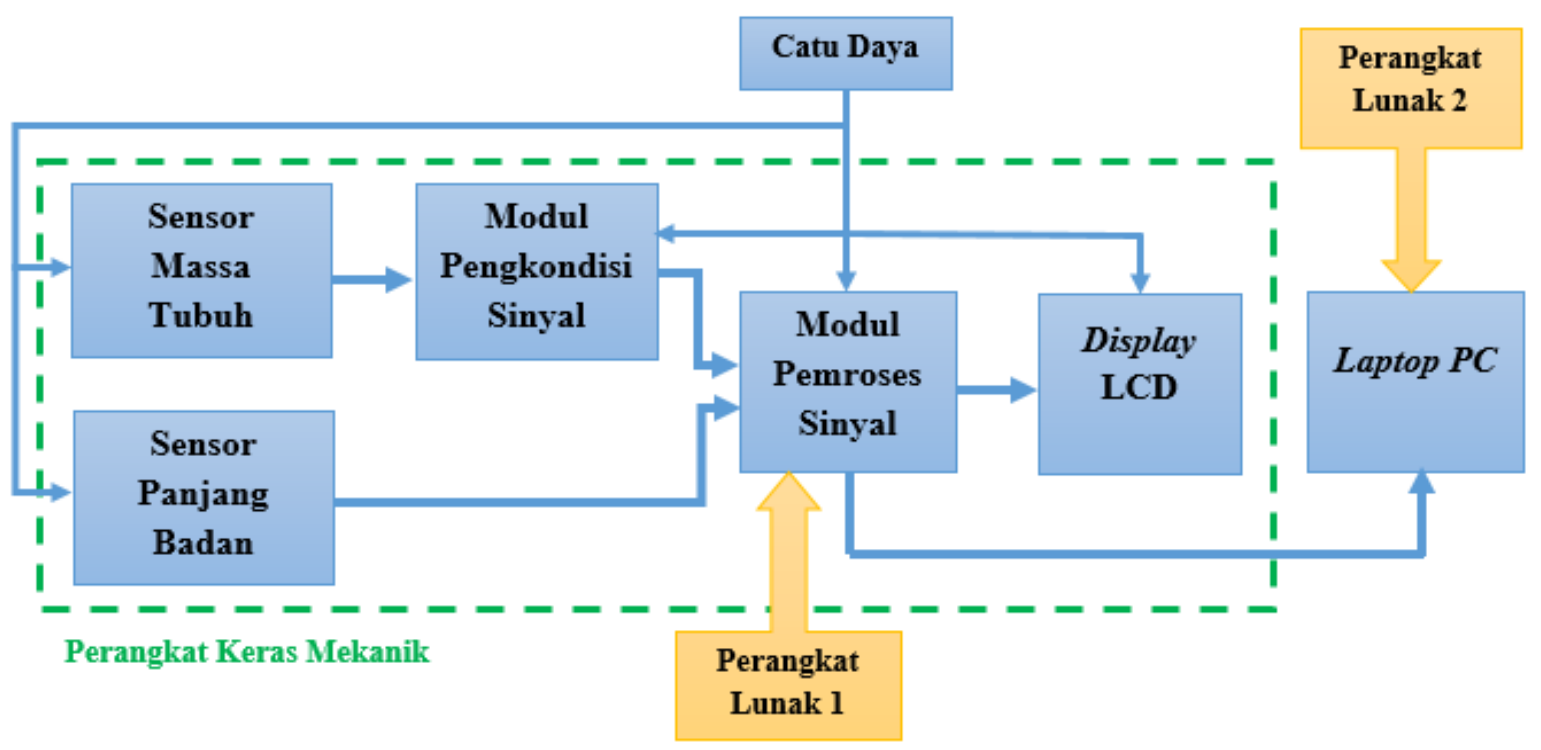

Gambar 1. Blok Diagram Sistem

\subsection{Perancangan Perangkat Keras Elektronik}

Sistem perangkat keras elektronik dirancang secara optimal agar alat mampu melakukan pengukuran massa tubuh dan panjang badan dengan baik dan dapat berkomunikasi secara serial dengan sebuah perangkat Laptop PC. Sistem pada perangkat keras elektronik dimana alat ukur massa tubuh berbasis sensor strain gauge dirangkai dengan menggunakan rangkaian jembatan Wheatstone, kemudian dihubungkan dengan modul HX711 untuk dikonversikan dan dikuatkan sinyalnya. Setelah itu, hasil keluaran dari modul HX711 dikirimkan ke sistem modul Arduino Nano untuk memproses data. Alat ukur panjang badan berbasis transducer ultrasonik dihubungkan ke modul Arduino Nano untuk memproses data yang masuk dari transducer. Setelah data dari alat ukur massa tubuh dan panjang badan diproses pada modul Arduino Nano, kemudian hasilnya ditampilkan pada layar LCD. Hasil pengukuran dari modul Arduino Nano dikirimkan juga ke Laptop $P C$ melalui komunikasi data secara serial untuk ditampilkan pada layar Laptop PC dan kemudian disimpan pada program basis data.

\subsection{Perancangan Perangkat Keras Mekanik}

Pada perancangan sistem perangkat keras mekanik dilakukan desain dan realisasi alat ukur massa tubuh dan panjang badan untuk balita secara terintegrasi. Alat tersebut terbuat dari kayu yang dipilih agar dapat digunakan untuk menempatkan balita. Alat dibuat seperti bentuk sebuah box dimana pada bagian dalamnya dapat ditempatkan seorang balita dengan posisi dalam keadaan telentang untuk diukur massa tubuh dan panjang badannya secara bersamaan. Ukuran box tersebut memiliki panjang $120 \mathrm{~cm}$ dan lebar $50 \mathrm{~cm}$. Ukuran box dipilih agar dapat mengukur balita dari lahir sampai dengan usia 2 tahun. Berdasarkan standar antropometri penilaian status gizi pada rentang usia tersebut, panjang balita akan berkisar mulai dari $40 \mathrm{~cm}$ sampai dengan $97 \mathrm{~cm}$ (Depkes, 2011). Pada pengukuran dalam box, alat mampu mengukur panjang balita mulai dari $11 \mathrm{~cm}$ sampai dengan $103 \mathrm{~cm}$. Dengan demikian, alat ini dapat digunakan untuk balita pada rentang usia tersebut. Gambar desain box balita tersebut seperti yang terdapat pada Gambar 2. 


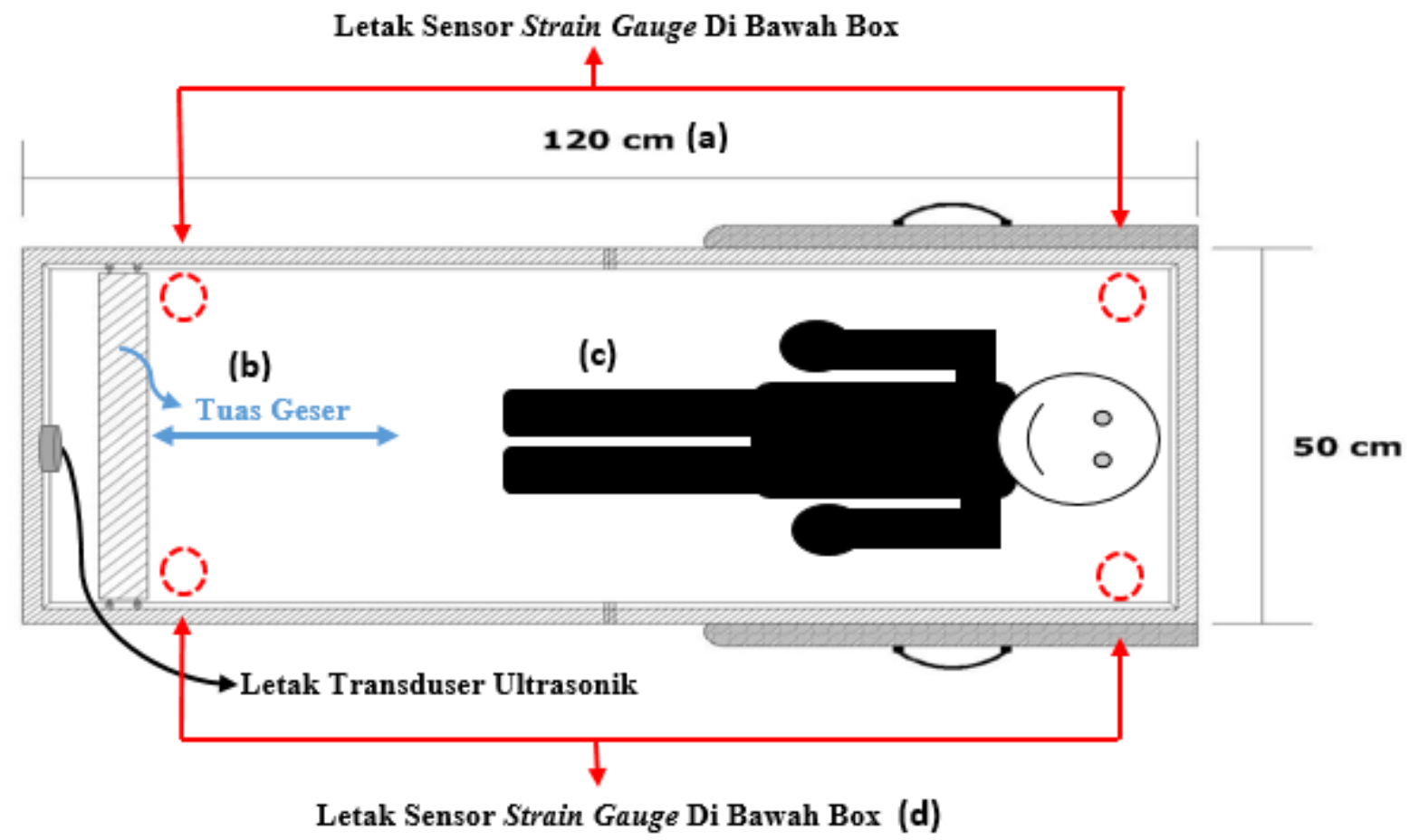

Gambar 2. Desain Box Alat Ukur Massa Tubuh dan Panjang Badan Balita

\subsection{Perancangan Perangkat Lunak}

Perancangan perangkat lunak meliputi perancangan program pada modul pemroses sinyal Arduino Nano dan perancangan program komunikasi data secara serial antara perangkat Laptop PC dengan alat ukur massa tubuh dan panjang badan yang berbasis PLX-DAQ. Secara umum, diagram alir program ditunjukkan pada Gambar 3 (a) dan 3 (b).

Pada modul pemrosesan sinyal sistem bekerja secara serial seperti Gambar 3 (a), proses pertama sistem membaca pengukuran dari alat ukur massa ketika objek tervalidasi (referensi) ditimbang. Arduino Nano membaca hasil pengukuran massa objek tersebut dalam bentuk bilangan biner. Nilai bilangan biner ini kemudian diolah menjadi besaran massa terukur. Nilai massa referensi ini kemudian dikalibrasikan dengan besaran massa terukur untuk mencari persamaan matematis yang menghubungkan antara nilai massa referensi $(y)$ dengan massa terukur ( $\mathrm{x}$ ). Persamaan matematis ini diperoleh dengan cara metoda pencocokan kurva melalui grafik linieritas pada program Microsoft Excel. Melalui persamaan tersebut, maka sistem melakukan pengukuran dan penampilan pengukuran massa. Lanjut ke proses kedua sistem membaca pengukuran panjang badan, nilai waktu tempuh pada pengiriman sinyal datang dan sinyal pantul masuk, kemudian menghitung selisih nilai waktu tempuh sinyal datang dan pantul. Setelah nilai pengukuran massa tubuh dan panjang badan diolah kemudian hasilnya ditampilkan pada layar LCD, dan dikirimkan ke Laptop PC melalui jalur komunikasi port serial.

Tahap kedua yaitu perancangan program pada Laptop $P C$, dimana sistem kerjanya seperti pada Gambar 3 (b). Pada Laptop PC proses pertama data hasil pengukuran dari modul pemroses sinyal diterima oleh $L a p t o p P C$, kemudian data hasil tersebut ditampilkan pada layar Laptop PC, setelah itu data hasil disimpan pada basis data. 

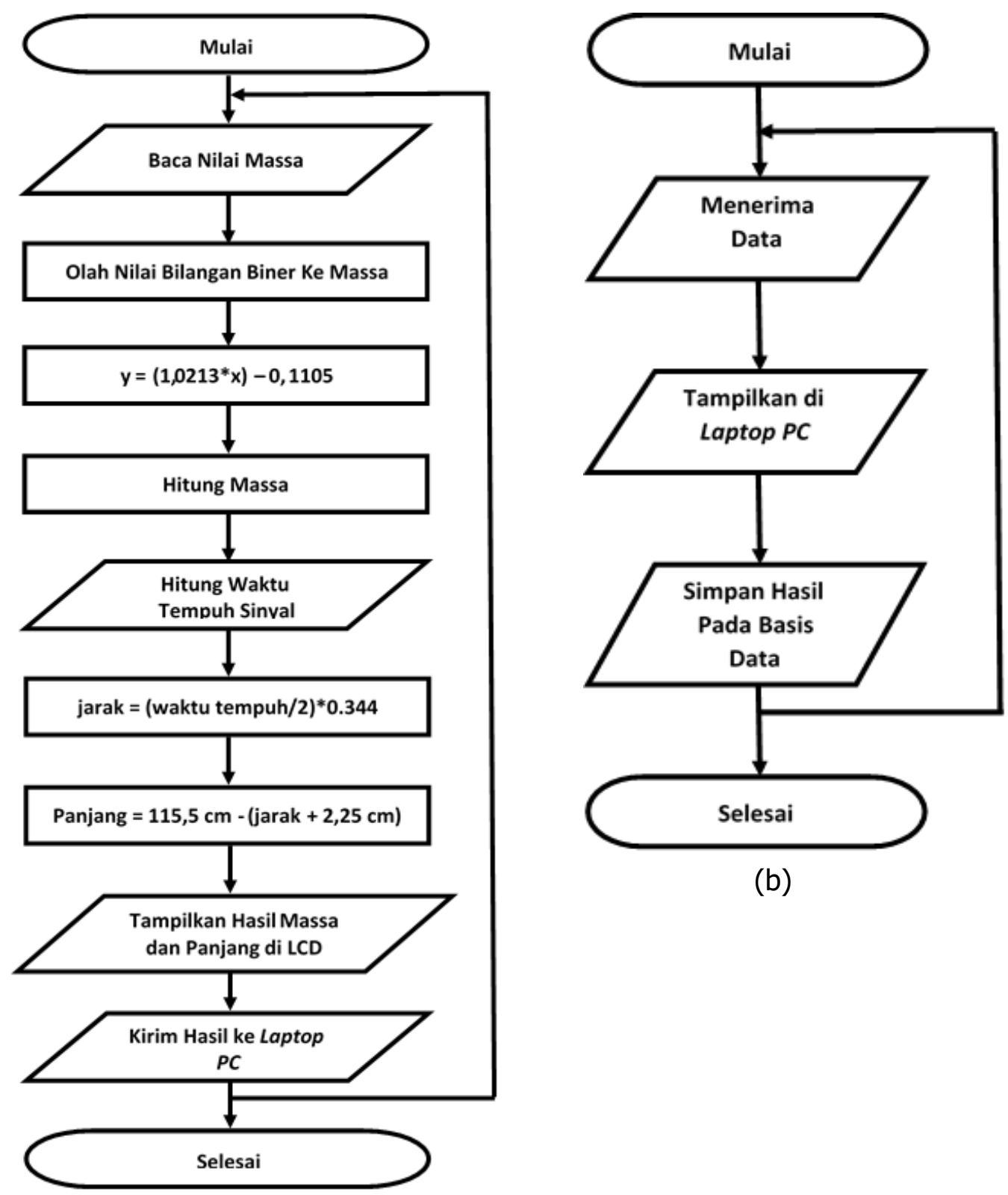

(b)

(a)

\section{Gambar 3. (a) Flowchart Sistem pada Modul Pemroses Sinyal (b) Flowchart Sistem pada Laptop PC}

\subsection{Metodologi Pengujian}

Pada penelitian ini dilakukan lima jenis metodologi pengujian. Metodologi pengujian pertama meliputi pengujian kinerja alat ukur massa tubuh yang bertujuan untuk mengetahui tingkat kepresisian, linearitas dan akurasi. Pengujian dilakukan dengan mengukur massa beban per 100 gram mulai dari $0 \mathrm{~kg}$ sampai dengan $30 \mathrm{~kg}$, dimana massa beban yang digunakan merupakan beban yang telah ditera dan ditimbang ulang pada alat timbangan tervalidasi lainnya. Massa beban dari hasil peneraan dan penimbangan dengan alat ukur timbangan tervalidasi lainnya dijadikan sebagai data referensi. Pengujian pengukuran massa pada alat yang dirancang dengan sejumlah massa beban tersebut dilakukan sebanyak 3 kali. Metodologi pengujian kedua yaitu pengujian kinerja alat ukur panjang badan yang bertujuan untuk mengetahui tingkat kepresisian, linearitas dan akurasi. Pengujian dilakukan dengan melakukan pengukuran panjang setiap $1 \mathrm{~cm}$ dalam rentang panjang $20-105 \mathrm{~cm}$. Pengujian ini dilakukan 
sebanyak tiga kali. Sebagai data referensi panjang pembanding digunakan dua buah meteran tervalidasi yang ditempel pada bagian kedua sisi alat. Metodologi pengujian yang ketiga meliputi pengujian dengan mengukur 10 buah objek yang terbuat dari pipa yang diisi pasir dengan massa dan panjang yang disesuaikan data standar massa dan panjang tubuh balita pada usia tertentu. Pengukuran ini dilakukan sebanyak lima kali. Metodologi pengujian yang keempat meliputi pengujian dengan mengukur waktu pada saat pengukuran massa tubuh dan panjang badan. Dengan tujuan untuk mengetahui berapa lama waktu untuk melakukan pengukuran massa tubuh dan panjang badan dengan alat ukur yang telah direalisasikan. Hasil perhitungan waktu ini selanjutnya dibandingkan dengan waktu pengukuran massa tubuh yang dilakukan di Posyandu dengan menggunakan alat ukur manual. Pengujian menggunakan 10 buah objek, pengukuran ini dilakukan sebanyak 3 kali. Metodologi pengujian kelima dilakukan dengan mengukur massa tubuh yang kemudian hasilnya akan ditampilkan pada grafik KMS digital. Metode pengujian dengan mengukur massa tubuh 10 buah objek yang diibaratkan 10 buah objek tersebut adalah 1 balita yang diukur pada saat usia yang berbeda-beda. Selain itu dari hasil pengujian yang kelima ini sistem dapat menampilkan evaluasi status gizi balita secara otomatis.

\section{HASIL PENELITIAN DAN ANALISIS}

Pada bab ini berisi tentang hasil pengujian kinerja alat ukur massa tubuh dan panjang badan untuk mengetahui tingkat kepresisian, linearitas dan akurasi. Serta pengujian terhadap 10 buah objek. Pada bab ini juga dibahas mengenai analisis data dari hasil pengujian yang telah dilakukan.

\subsection{Pengujian Pertama}

Dari pengujian pertama didapat hasil pengujian berdasarkan referensi beban per $100 \mathrm{gram}$ mulai dari $0-30 \mathrm{~kg}$. Hasil tersebut kemudian diolah untuk mendapatkan nilai lineritas, akurasi dan kepresisian. Hasil pengujian nilai linieritas dan akurasi massa ditunjukkan pada Gambar 4 dan Gambar 5.

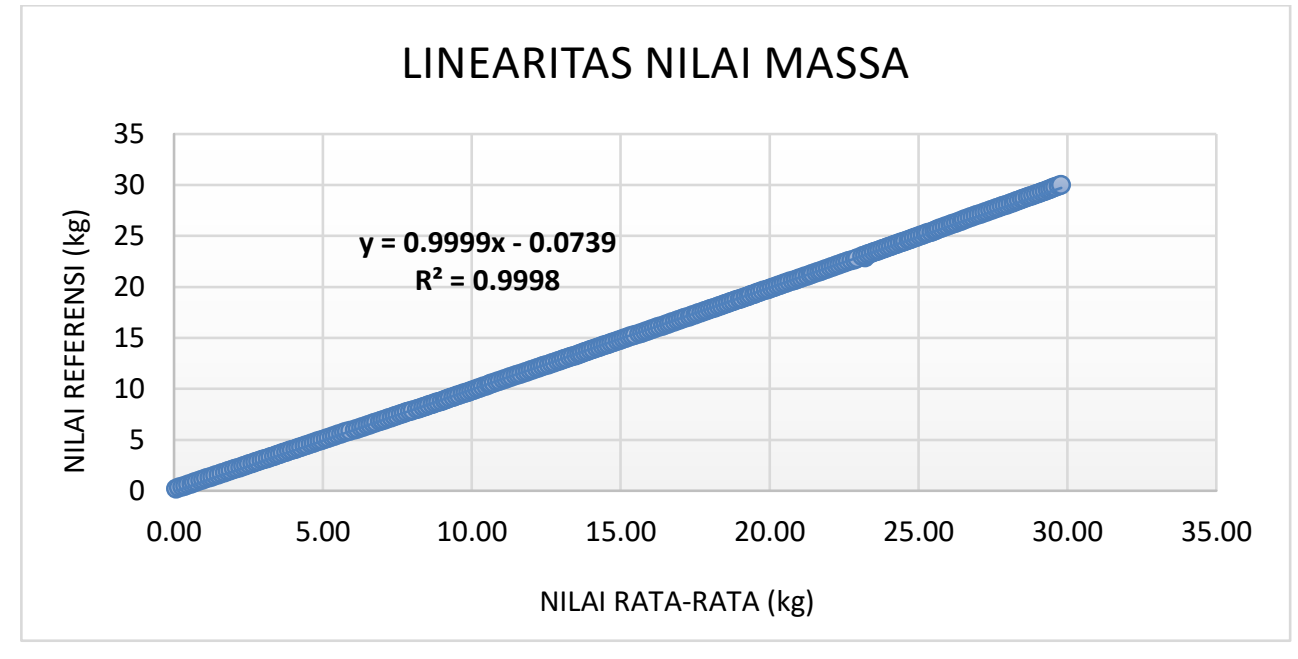

Gambar 4. Grafik Lineritas Nilai Massa

Grafik lineritas rata-rata massa terhadap massa referensi menunjukkan nilai linearitas $\mathrm{R}^{2}=$ 0,9998 . Jika dilihat nilai linearitas $R^{2}$ maka dapat dinyatakan bahwa hasil pengukuran sangat linear. Untuk pengujian nilai akurasi massa tubuh didapatkan rata-rata error sebesar $0,19 \mathrm{~kg}$. Nilai erroryang didapat masih di atas nilai ketelitian 100 gram yang dirancang. Nilai erroryang diharapkan yaitu bernilai nol atau paling tidak di bawah 100 gram. Pada grafik akurasi nilai 
massa tubuh (Gambar 5) terlihat error yang paling besar terjadi pada saat pengukuran beban $22,9 \mathrm{~kg}$ dengan nilai error 0,43 kg. Nilai-nilai error yang terjadi disebabkan oleh beberapa faktor mulai dari posisi peletakan sensor dimana posisi sensor harus tepat dengan kondisi alat yang berbentuk persegi panjang (bukan bujur sangkar) agar penyebaran sensor dapat merata ke seluruh luas alat. Kemudian penempatan beban pada saat kalibrasi yang seharusnya ditempatkan pada titik tengah massa.

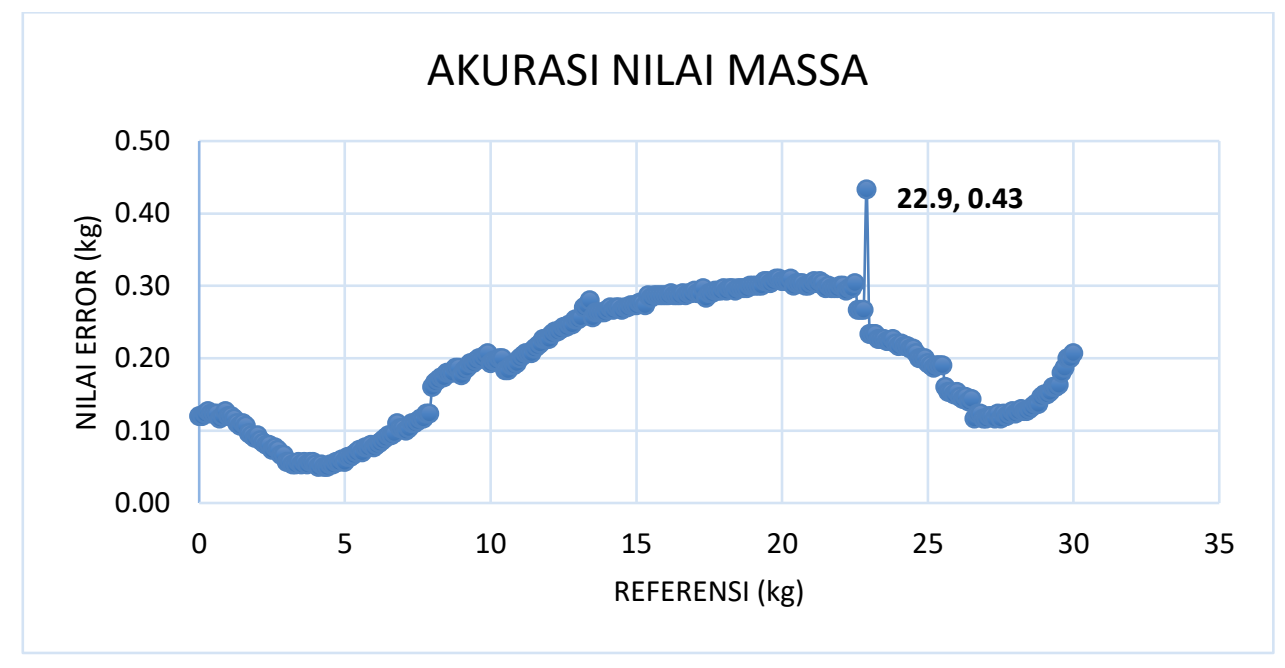

\section{Gambar 5. Grafik Akurasi Nilai Massa}

Pada Gambar 6 ditunjukkan grafik kepresisian nilai massa dari 3 kali pengukuran. Nilai ratarata kepresisisan yang didapat sebesar $0,15 \mathrm{~kg}$ yang seharusnya nilai presisi yang baik adalah nol. Pada grafik kepresisian terlihat nilai error presisi paling besar yaitu $0,41 \mathrm{~kg}$ pada nilai pengukuran rata-rata sebesar $23,21 \mathrm{~kg}$.

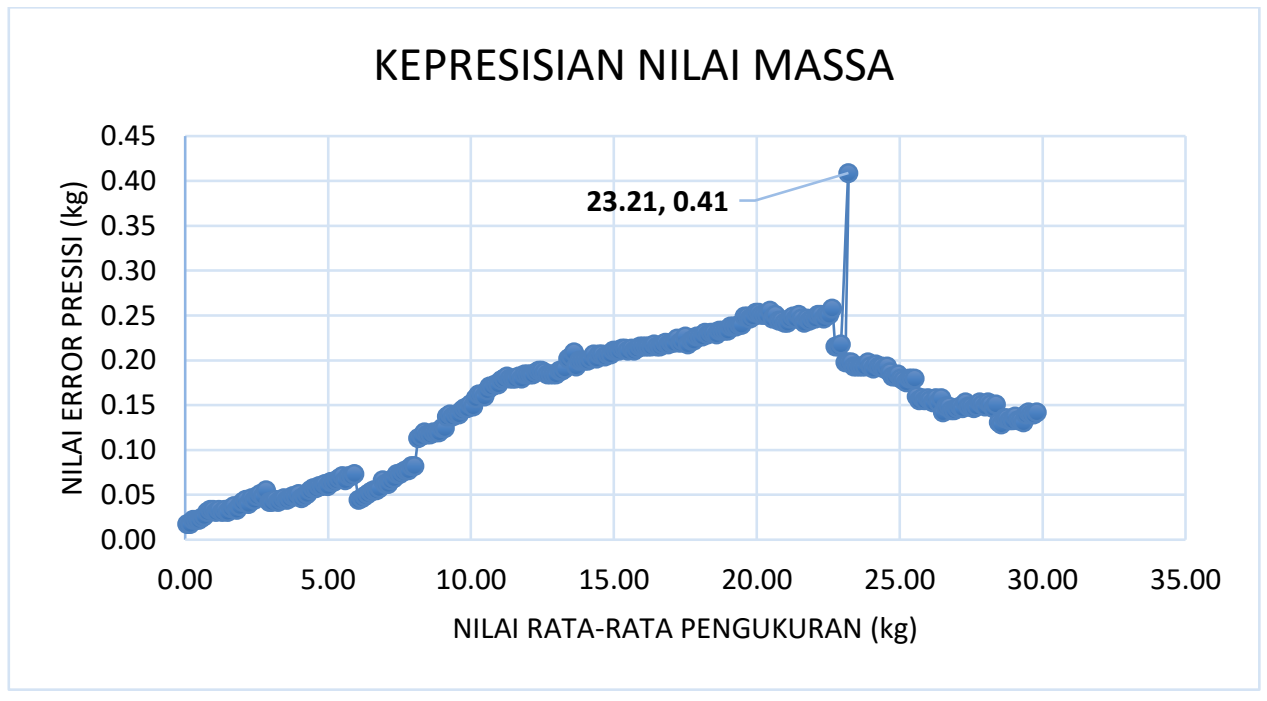

Gambar 6. Grafik Kepresisian Nilai Massa

\subsection{Pengujian Kedua}

Dari pengujian kedua didapat hasil pengujian per setiap $1 \mathrm{~cm}$ berdasarkan referensi panjang mulai dari $20-105 \mathrm{~cm}$. Hasil tersebut kemudian diolah untuk mendapatkan nilai lineritas, akurasi dan kepresisian. Hasil pengujian nilai linieritas, akurasi dan presisi ditunjukkan pada Gambar 7, Gambar 8 dan Gambar 9. Grafik lineritas rata-rata panjang terhadap panjang 
referensi seperti yang terlihat pada Gambar 7 menunjukkan bahwa nilai linearitas $R^{2}=0,9999$. Jika dilihat nilai linearitas $\mathrm{R}^{2}$ maka dapat dinyatakan bahwa hasil pengukuran sangat linear. Pada grafik akurasi (Gambar 8) dapat nilai rata-rata error sebesar 0,54 cm dimana nilai error tersebut masih dalam batas wajar karena mengingat nilai error masih di bawah nilai ketelitain yang dikehendaki yaitu $1 \mathrm{~cm}$. Nilai error terbesar terjadi pada saat pengukuran $41 \mathrm{~cm}$ dengan nilai error sebesar $1,20 \mathrm{~cm}$.

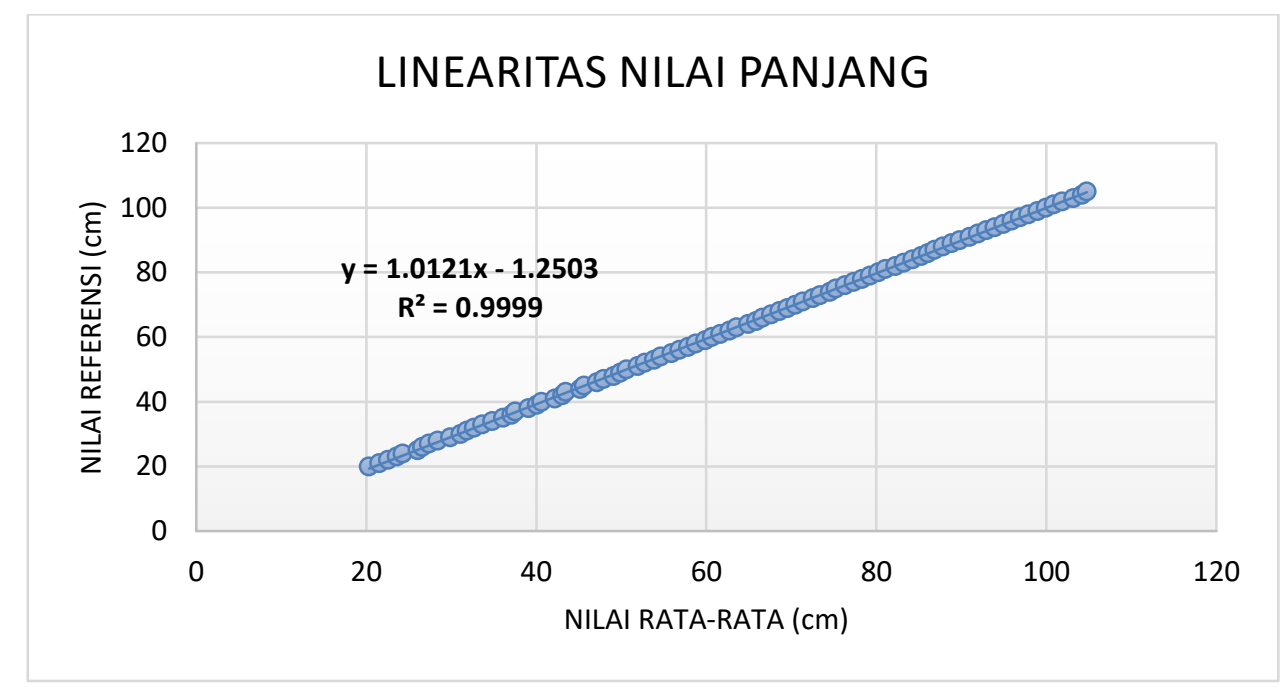

Gambar 7. Grafik Lineritas Nilai Panjang

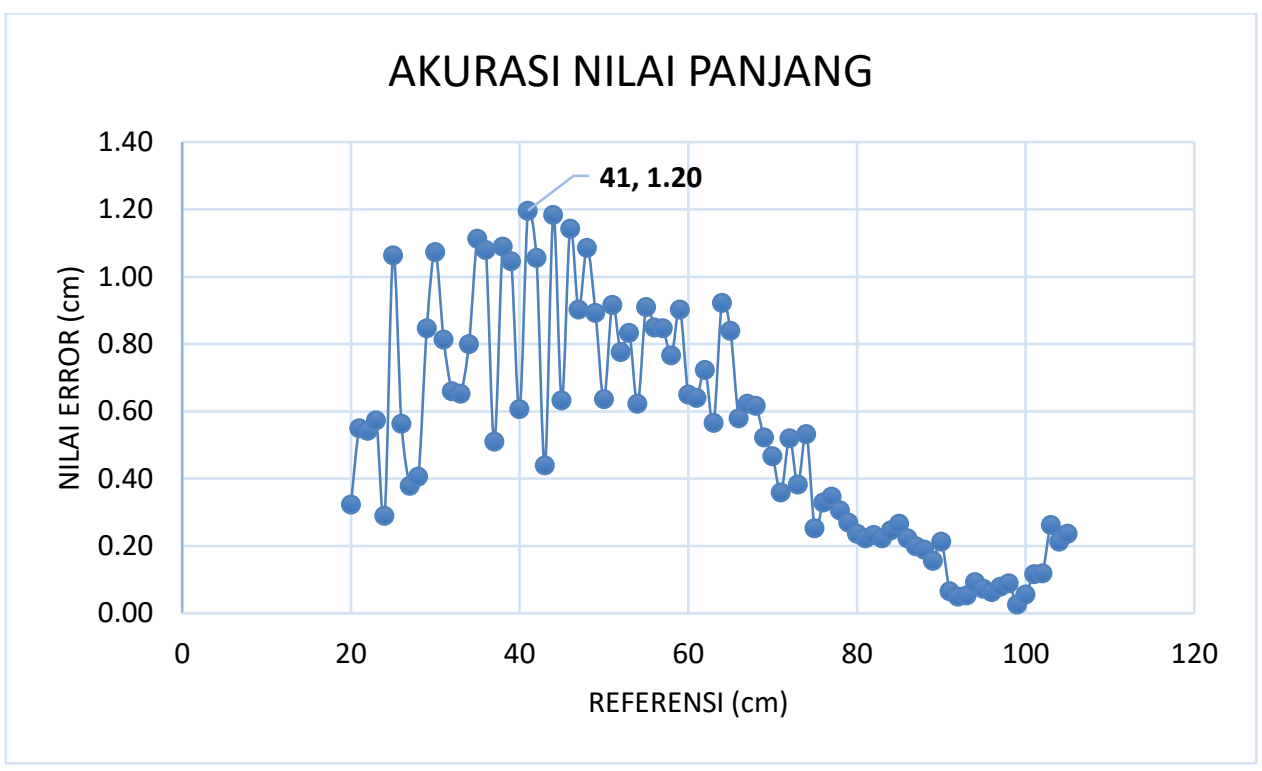

Gambar 8. Grafik Akurasi Nilai Panjang

Untuk nilai rata-rata kepresisian alat ukur panjang badan yang didapatkan yaitu sebesar 0,12 $\mathrm{cm}$ yang seharusnya nilai presisi yang baik adalah nol. Nilai presisi yang didapatkan tidak begitu besar dengan kata lain masih berada pada batas kondisi yang wajar. Nilai error presisi paling besar terjadi pada saat nilai pengukuran $64,92 \mathrm{~cm}$ dengan nilai error presisi sebesar $0,53 \mathrm{~cm}$ seperti yang terlihat gambar grafik kepresisisan (Gambar 9). 


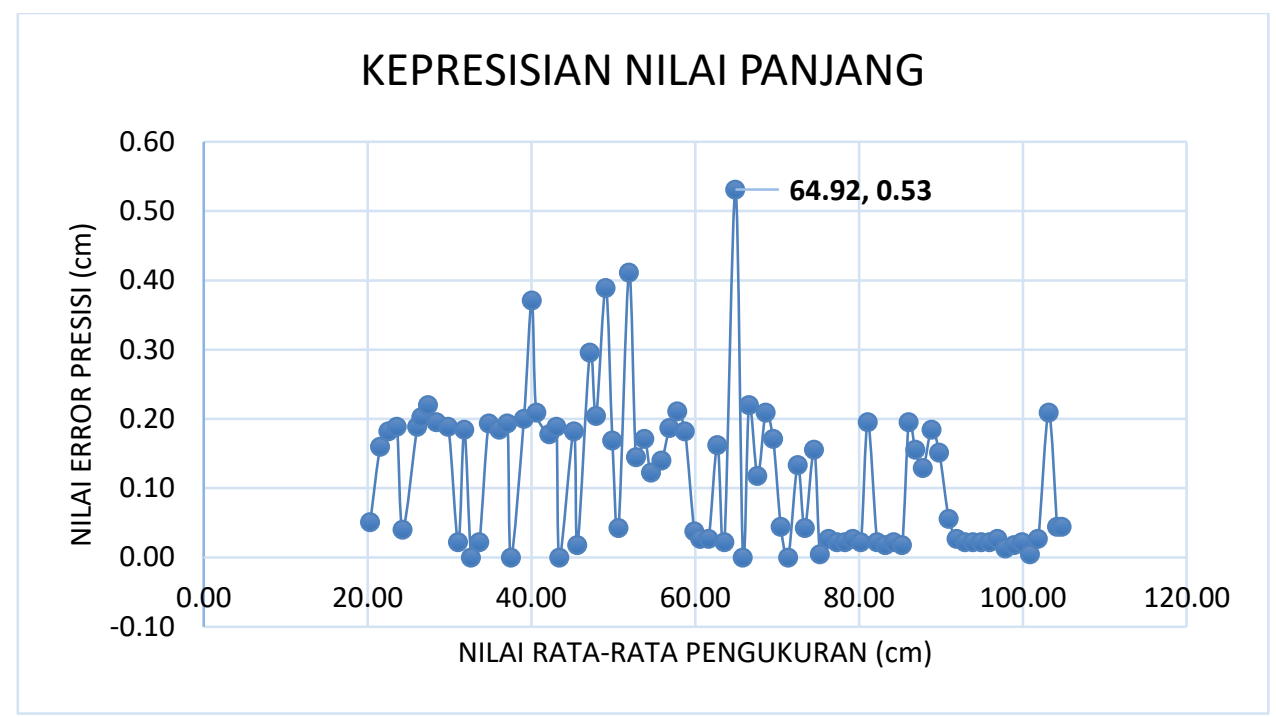

Gambar 9. Grafik Kepresisisan Nilai Panjang

\subsection{Pengujian Ketiga}

Dari pengujian ketiga didapat hasil pengujian massa tubuh dan panjang badan dari 10 buah objek yang dibuat dengan massa tubuh dan panjang standar balita dalam rentang usia $0-24$ bulan. Hasil pengujian ditunjukkan pada Gambar 10 dan Gambar 11.

Dari pengujian objek yang dilakukan sebanyak 5 kali kemudian dirata-ratakan, didapat hasil pengukuran massa tubuh yang terlihat pada Gambar 10 dimana nilai referensi dengan nilai pengukuran tidak begitu jauh. Terlihat masih ada error, dimana error terbesar yaitu $0,26 \mathrm{~kg}$ pada saat pengukuran objek ke-9 dan ke-10. Kondisi tersebut dipengaruhi posisi peletakan sensor pada box persegi panjang, dengan menempatkan pada posisi yang tepat mungkin akan mempengaruhi kualitas pengukuran. Selain itu, perbaikan dapat dilakukan dengan memperbaiki program dengan proses kalibrasi.

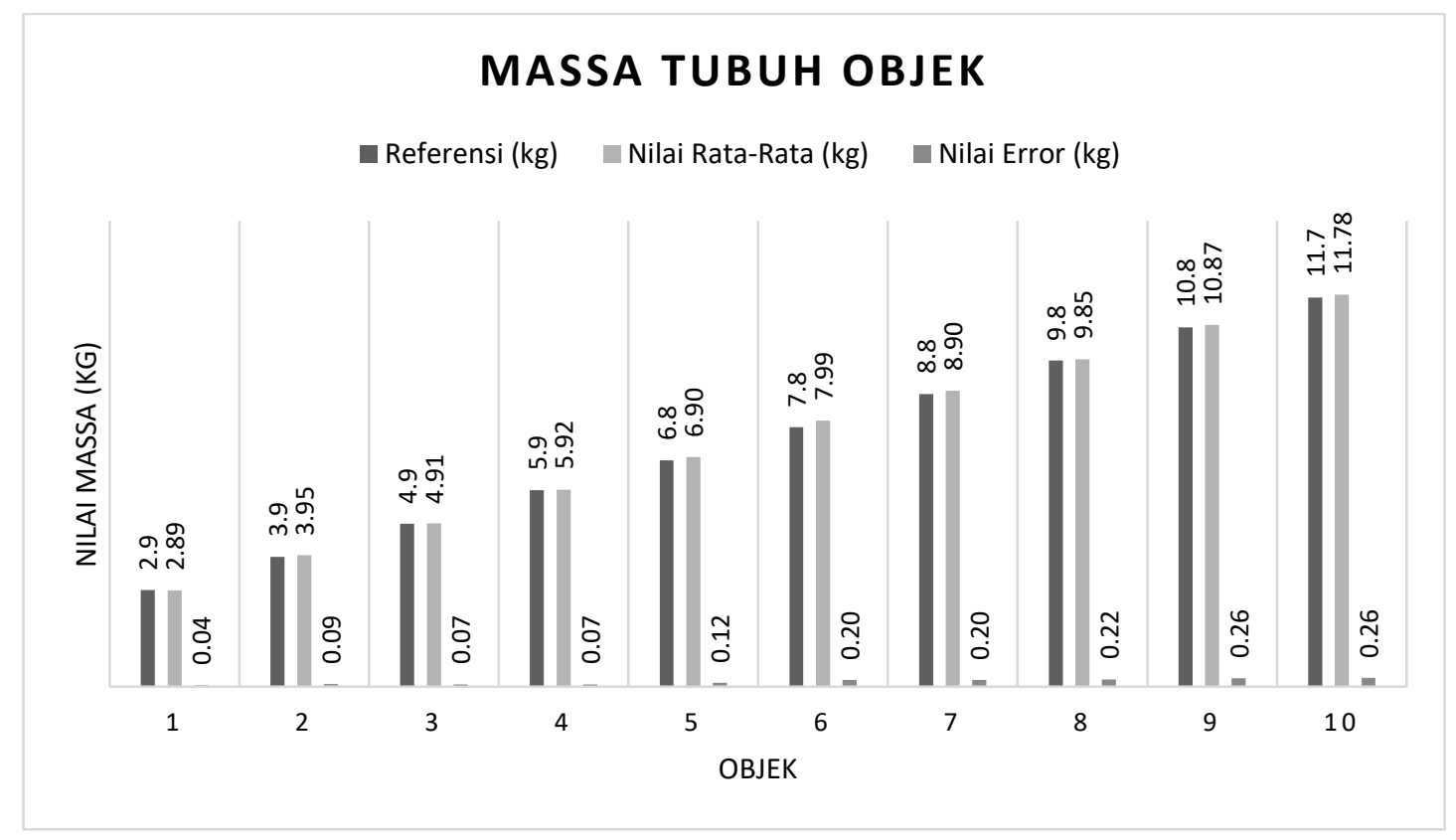

Gambar 10. Grafik Pengukuran Massa Tubuh Objek 


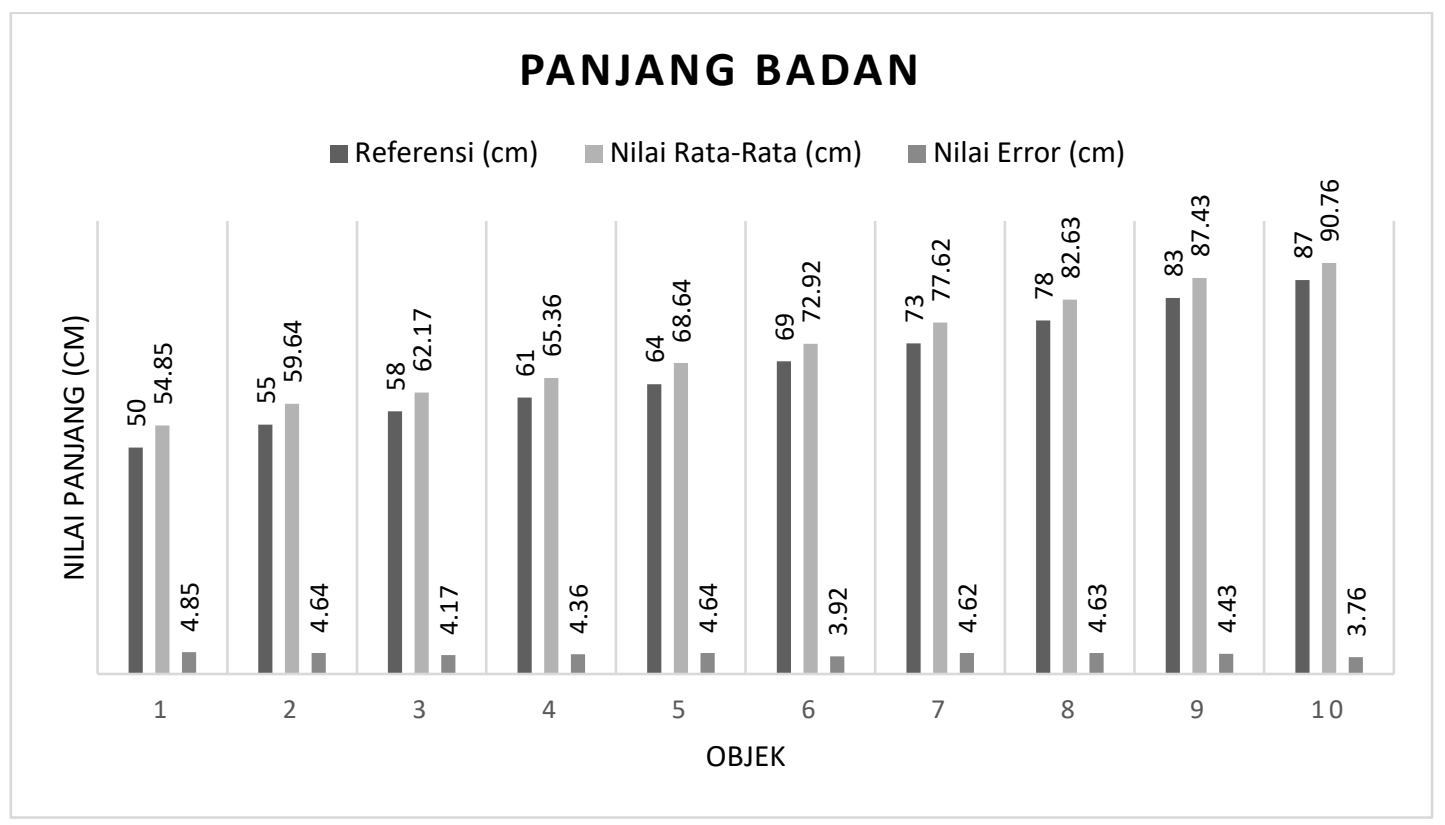

Gambar 11. Grafik Pengukuran Panjang Badan Objek

Untuk pengukuran panjang badan yang terlihat pada Gambar 11 dimana terlihat ada perbedaan tinggi garis referensi dengan hasil pengukuran. Adanya nilai erroryang cukup besar yaitu sekitar $4,85 \mathrm{~cm}$ pada saat pengukuran objek ke-1, seharusnya nilai error adalah nol atau paling tidak $1 \mathrm{~cm}$ sesuai dengan spesfikasi ketelitian alat yang diinginkan. Hal itu disebabkan oleh beberapa faktor seperti transducer ultrasonik kurang maksimal pada saat digunakan di dalam sebuah box alat ukur panjang badan. Padahal jika dilihat pada banyak penelitian sebelumnya [Sarah, 2014] telah membuktikan bahwa alat ukur tinggi badan berbasis transducer ultrasonik sangat baik dan mampu mengukur sampai sejauh $200 \mathrm{~cm}$.

Akan tetapi, hal tersebut memang terjadi apabila sensor digunakan pada kondisi di luar box (tanpa penghalang di samping kiri dan kanan transducer). Pada kondisi di dalam box, papan yang berada di samping kiri dan kanan mempengaruhi transducersehingga tidak dapat bekerja dengan baik. Hal ini disebabkan karena sinyal yang dikirimkan tranducer akan memantul pada pinggiran box sebelum mencapai objek yang dituju. Melihat kondisi seperti itu maka perlu dilakukan upaya untuk memperbaiki alat ukur dengan melepas papan pada box yang berada di pinggir agar dapat memperbaiki kinerja transducer ultrasonik. Akan tetapi, upaya tersebut sulit dilakukan karena melihat kontruksi box yang diperlukan yaitu jika papan yang berada di pinggir dilepas maka dapat mempengaruhi tuas geser menjadi tidak dapat berdiri tegak. Padahal kedua papan tersebut berfungsi sebagai penopang tuas geser yang berbentuk datar guna mengurangi errorpengukuran. Papan datar tersebut digunakan sebagai ketinggian objek yang dapat memantulkan gelombang ultrasonik dengan lebih baik. Hasil pengujian ini juga telah sama terbukti dengan penelitian dari Carullo dan Parvis yang meneliti tentang pengukuran jarak yang digunakan pada kendaraan dalam keadaan bergerak, dimana hasilnya menunjukkan bahwa pengukuran jarak untuk benda yang datar menghasilkan ketelitian yang lebih baik [Carullo dan Parvis, 2001]. Dengan begitu upaya memperbaiki faktor penyebab error tidak bisa dilakukan dengan mengubah konstruksi alat.

Cara lain untuk mengatasi masalah tersebut adalah perlu dilakukan upaya perbaikan sistem pada program alat ukur panjang badan. Salah satu metoda pengolahan sinyalnya adalah 
dengan menggunakan penggabungan teknik time of flight dan phase shift untuk mengolah sinyal ultrasonik yang ditransmisikan dan diterima oleh modul pengolah sinyal [Gueuning, $\mathbf{F}$. dan rekan, 1996]. Dengan metoda ini telah terbukti pada penelitian tersebut bahwa dapat mengurangi error selain error dari kontruksi box yaitu error yang ditimbulkan dari suhu di sekeliling lingkungan pengukuran.

\subsection{Pengujian Keempat}

Dari prosedur percobaan waktu pengukuran massa tubuh dan panjang badan yang telah dilakukan untuk mengetahui tingkat efisiensi waktu pengukuran dengan alat yang telah diimplementasikan. Hasil pengujian akan dibandingkan dengan data waktu pengukuran yang telah dilakukan di Posyandu dengan menggunakan alat ukur berat badan manual. Data hasil pengujian yang telah dilakukan sebanyak 3 kali ditunjukan pada Tabel 1.

Pada Tabel 1 terlihat hasil pengujian waktu pengukuran massa tubuh dan panjang badan dengan menggunakan 10 buah objek. Pengujian dilakukan dengan kondisi objek yang ideal artinya tidak adanya faktor psikologis dari balita. Untuk data waktu referensi didapat dari hasil pengukuran berat badan balita saja tanpa pengukuran panjang badan, dikarenakan untuk proses pengukuran panjang badan tidak dilakukan. Hasil pengujian menunjukan total rata-rata waktu pengukuran massa tubuh dan panjang badan sebesar 4,62 detik, sedangkan untuk total rata-rata waktu referensi sebesar 25,51 detik. Dari analisis kedua data tersebut menunjukkan hasil perbedaan waktu yang cukup jauh, artinya alat ukur massa tubuh dan panjang badan yang diimplementasikan memiliki waktu pengukuran yang lebih efisisen.

Tabel 1. Hasil Pengujian Waktu Pengukuran Massa Tubuh dan Panjang Badan

\begin{tabular}{|c|c|c|c|c|c|}
\hline \multirow{2}{*}{ OBJEK } & \multirow{2}{*}{$\begin{array}{l}\text { REFERENSI } \\
\text { (detik) }\end{array}$} & \multicolumn{3}{|c|}{ PENGUKURAN WAKTU (detik) } & \multirow{2}{*}{$\begin{array}{c}\text { RATA-RATA } \\
\text { WAKTU } \\
\text { PENGUKURAN } \\
\text { (detik) } \\
\end{array}$} \\
\hline & & WAKTU 1 & WAKTU 2 & WAKTU 3 & \\
\hline 1 & 19,17 & 3,9 & 6,11 & 5,3 & 5,10 \\
\hline 2 & 19,06 & 5,35 & 3,97 & 3,98 & 4,43 \\
\hline 3 & 20,68 & 4,43 & 7,61 & 3,22 & 5,09 \\
\hline 4 & 19,06 & 7,12 & 5,05 & 4,72 & 5,63 \\
\hline 5 & 38,48 & 5,61 & 4,4 & 3,79 & 4,60 \\
\hline 6 & 29,59 & 4,02 & 4,59 & 4,49 & 4,37 \\
\hline 7 & 33,28 & 5,28 & 4,84 & 3,24 & 4,45 \\
\hline 8 & 20,38 & 4,6 & 4,09 & 2,68 & 3,79 \\
\hline 9 & 36,19 & 4,16 & 4,06 & 5,22 & 4,48 \\
\hline 10 & 19,22 & 4,81 & 4,57 & 3,32 & 4,23 \\
\hline $\begin{array}{l}\text { Total Rata- } \\
\text { Rata Ref }\end{array}$ & 25,51 & \multicolumn{3}{|c|}{ Total Rata-Rata Ukur } & 4,62 \\
\hline
\end{tabular}

\subsection{Pengujian Kelima}

Dari prosedur percobaan telah dilakukan untuk menampilkan hasil pengukuran massa tubuh pada KMS digital yang telah dibuat. Pengujian menggunakan sebuah 10 objek yang diibaratkan seorang balita dengan usia yang berbeda. Data hasil pengujian ditampilkan pada KMS digital yang ditunjukan pada Gambar 12. Pengujian kelima ini merupakan suatu langkah untuk menguji keseluruhan sistem baik dari pengukuran massa tubuh, panjang badan, komunikasi data, perekaman/penampilan data dan e valuasi status gizi balita (Tabel 2 ). 


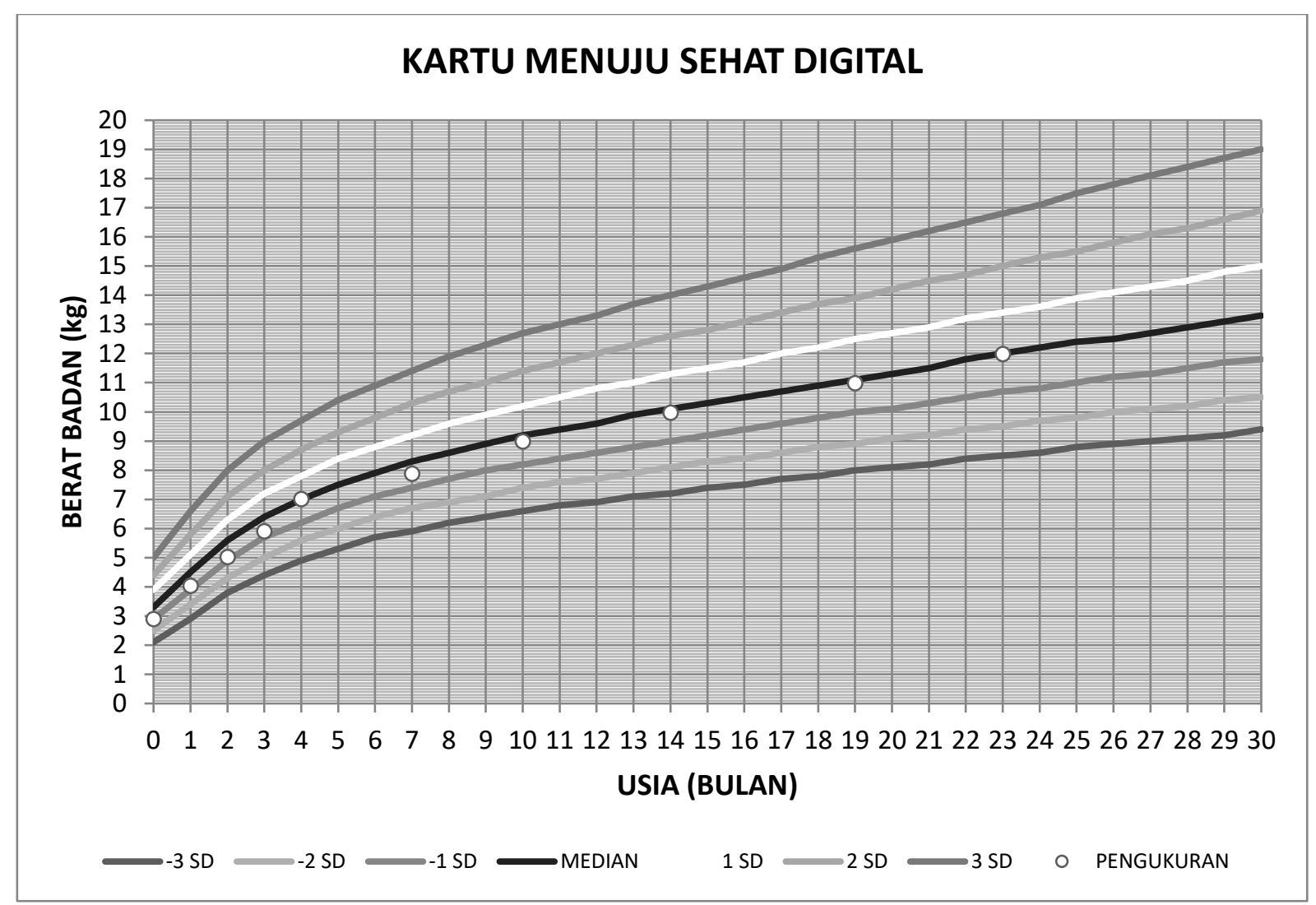

Gambar 12. Tampilan KMS Digital

Tabel 2. Hasil Pengukuran Massa Tubuh dan Status Gizi

\begin{tabular}{|c|c|c|c|}
\hline OBJEK & $\begin{array}{c}\text { UMUR } \\
\text { (bulan) }\end{array}$ & $\begin{array}{c}\text { PENGUKURAN BERAT BADAN } \\
(\mathbf{k g})\end{array}$ & $\begin{array}{c}\text { STATUS } \\
\text { GIZI }\end{array}$ \\
\hline 1 & 0 & 2,9 & GIZI BAIK \\
\hline 2 & 1 & 4,0 & GIZI BAIK \\
\hline 3 & 2 & 5,0 & GIZI BAIK \\
\hline 4 & 3 & 5,9 & GIZI BAIK \\
\hline 5 & 4 & 7,0 & GIZI BAIK \\
\hline 6 & 7 & 7,9 & GIZI BAIK \\
\hline 7 & 10 & 9,0 & GIZI BAIK \\
\hline 8 & 14 & 10,0 & GIZI BAIK \\
\hline 9 & 19 & 11,0 & GIZI BAIK \\
\hline 10 & 23 & 12,0 & GIZI BAIK \\
\hline
\end{tabular}

\section{KESIMPULAN}

Dari hasil penelitian ini dapat ditarik kesimpulan bahwa alat pengukur massa tubuh dan panjang badan elektronik terintegrasi untuk evaluasi gizi balita menggunakan sensor strain gauge dan transducer ultrasonik memiliki tingkat linearitas yang baik. Dilihat dari hasil pengujian sebanyak tiga kali didapatkan nilai linieritas massa tubuh sebesar $R^{2}=0,9998$ dan 
nilai lineritas panjang badan sebesar $\mathrm{R}^{2}=0,9999$. Untuk tingkat kepresisian diperoleh bahwa alat ukur massa tubuh dan panjang badan ini memiliki nilai kepresisian yang cukup baik, dimana nilai kepresisian yang diperoleh sebesar $0,15 \mathrm{~kg}$ dan $0,12 \mathrm{~cm}$. Walaupun tidak mencapai nilai nol tetapi angka tersebut masih tidak jauh dari nilai ketelitian alat.

Pada tingkat akurasi alat ukur massa tubuh terlihat masih adanya nilai-nilai error. Dari pengujian objek yang dilakukan sebanyak 5 kali kemudian dirata-ratakan, didapat hasil pengukuran massa tubuh terlihat masih ada error dimana errorterbesar yaitu 0,26 kg. Kondisi tersebut dipengaruhi posisi peletakan sensor pada box persegi panjang, dengan menempatkan pada posisi yang tepat mungkin akan mempengaruhi kualitas pengukuran. Atau dengan memperbaiki program dengan proses kalibrasi.

Pada tingkat akurasi alat ukur panjang badan diperoleh hasil yang kurang baik yaitu dilihat dari nilai error sebesar 4,85 cm. Dimana angka tersebut sangat tinggi jika dibandingkan dengan spesifikasi akurasi sistem yang dirancang yaitu sebesar $1 \mathrm{~cm}$. Seharusnya nilai error berada di bawah nilai ketelitian atau bahkan akan lebih baik bernilai nol. Hal ini disebabkan oleh adanya beberapa faktor terutama pada faktor transducer ultrasonik yang ternyata kurang maksimal apabila digunakan di dalam sebuah box alat ukur panjang badan. Untuk mengatasi masalah tersebut perlu dilakukan upaya perbaikan sistem pada program alat ukur panjang badan dan perbaikan pada sistem kontruksi tuas geser pada box alat.

Alat pengukur massa tubuh dan panjang badan elektronik terintegrasi untuk evaluasi gizi balita menggunakan sensor strain gauge dan transducer ultrasonik memiliki tingkat efisiensi waktu pengukuran yang sangat baik dengan rata-rata waktu pengukuran sebesar 4,65 detik. Untuk hasil pengukuran juga sudah dapat ditampilkan pada KMS digital dan juga dilengkapi penilaian status gizi balita.

\section{UCAPAN TERIMA KASIH}

Pada kesempatan ini penulis menyampaikan rasa terima kasih yang sebesar-besarnya kepada Kepala dan Staff Laboratorium Elektronika Jurusan Teknik Elektro Institut Teknologi Nasional yang telah memberikan tempat dan juga alat pendukung, sehingga penelitian ini dapat terlaksana dengan baik.

\section{DAFTAR RUJUKAN}

Anindya, S.F. dan Rachmat, H.H. (2015). Implementasi Sistem Bel Rumah Otomatis berbasis Sensor Ultrasonik. ELKOMIKA, 3(1), 64-74.

Carullo, A. dan Pervis, M. (2001). An Ultrasonic Sensor for Distance Measurement in Automotive Applications. IEEE SENSORS JOURNAL, 1(2).

Departemen Kesehatan. (2013). Gizi Seimbang Atasi Masalah Gizi Ganda. Kementrian Kesehatan Republik Indonesia. Jakarta. Dipetik 2 Maret 2016 dari http://www.depkes.go.id/article/view/2239/gizi-seimbang-atasi-masalah-giziganda.html\#sthash.oYY78gId.dpuf

Departemen Kesehatan. (2011). Standar Antropometri Penilaian Status Gizi Anak. Kementrian Kesehatan Republik Indonesia. Jakarta. 
Rancang Bangun Sistem Pengukur Massa Tubuh dan Panjang Badan Elektronik Terintegrasi untuk Evaluasi Gizi Balita

Dini, W, Sarah. (2014). Pengukur Tinggi Badan Digital Menggunakan Sensor Ultrasonik HCSRO4 Berbasis Arduino Uno. Jakarta.

Fajri, Nurul. (2014). Rancang Bangun Alat Ukur Alat Ukur Tinggi Dan Massa tubuh Bayi Berbasis Mikrokontroler Atmega8535 Dengan Sensor Fototransistor. Jurnal Fisika Unand, 3(3).

Gueuning, F., Varlan, M., Eugène, C., Dupuis, P. (1996). Accurate Distance Measurement by an Autonomous Ultrasonic System Combining Time-of-Flight and Phase-Shift Methods . IEEE Instrumentation and Measurement Technology Conference. Brussels, Belgium.

Kusumah, Hendra, Dkk. (2015). Sistem Pengukur Tinggi Dan Massa tubuh Untuk Posyandu Menggunakan Mikrokontroler Atmega8535. 9(2).

N, Siedle \& Wende, Alex. 2016. HX711 Load Cell Version 11. Dipetik 22 Maret 2016 dari https://www.sparkfun.com/products/retired/13230 